\title{
Peróxido de hidrogênio no controle de patógenos e do escurecimento enzimático de vagem minimamente processada
}

\author{
Maria Cecília de Arruda Palharini*, Claudia Aline de Júlio Pereira Santos², \\ 'Polo Regional Centro Oeste, APTA/SAA, Bauru, SP, Brasil \\ ${ }^{2}$ Ministério da Agricultura, Pecuaria e Abastecimento, Bauro, SP, Brasil \\ ${ }^{3}$ Universidade do Sagrado Coração, Bauro, SP, Brasil \\ ${ }^{4}$ Embrapa Mandioca e Fruticultura, Cruz das Almas, BA, Brasil \\ *Autor correspondente, e-mail: mcarruda@apta.sp.gov.br
}

Mirian de Souza Fileti', Eliane Maria Ravási Stéfano Simionato ${ }^{3}$, Fabiana Fumi Cerqueira Sasaki ${ }^{4}$

\begin{abstract}
Resumo
O objetivo deste trabalho foi avaliar a eficácia da sanificação com peróxido de hidrogênio em minimizar o escurecimento enzimático e reduzir patógenos em vagem minimamente processada. Vagens minimamente processadas foram inoculadas por imersão em solução contaminante de Escherichia coli e Salmonella enteritidis e sanificadas com peróxido de hidrogênio $10,5,10$ e $20 \mathrm{~mL}$ $\mathrm{L}^{-1}$ ) por 10 minutos. A população de patógenos foi monitorada imediatamente após a sanificação e no quarto dia de armazenamento a $10^{\circ} \mathrm{C}$. Em outro experimento similar, porém sem a inoculação dos patógenos, as vagens foram avaliadas periodicamente quanto à: coloração da superfície da casca e corte; $\mathrm{pH}$; atividade das enzimas fenilalanina-amônia-liase, peroxidase e polifenoloxidase; teor de clorofila e carotenoides. A sanificação reduziu a contagem de E. coli e S. enteritidis, sendo essa redução similar nas diferentes concentrações de peróxido. O escurecimento da superfície de

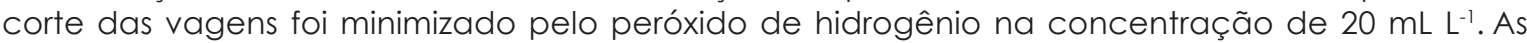
atividades das enzimas, assim como o teor de clorofila e carotenoides não foram afetados pelos tratamentos, exceto a polifenoloxidase. $\mathrm{O}$ pH aumentou durante o armazenamento, sendo maior nas vagens sanitizadas com $20 \mathrm{~mL} \mathrm{~L}^{-1}$ de peróxido. Conclui-se que a sanificação com peróxido de hidrogênio é eficaz em reduzir a população de E. coli e S. enteritidis bem como minimizar o escurecimento na superfície de corte da vagem, porém ocasiona manchas na casca das vagens minimamente processadas, inviabilizando sua utilização.
\end{abstract}

Palavras-chave: Phaseolus vulgaris L., microbiologia, qualidade, sanificação.

\section{Hydrogen peroxide on fresh cut snap bean pathogens control and enzymatic browning}

\begin{abstract}
The objective of this study was to evaluate the efficacy of sanitization with hydrogen peroxide in reducing the enzymatic browning and pathogens of fresh cut snap bean. Fresh cut snap beans were inoculated by immersion in an Escherichia coli and Salmonella enteritidis contaminant solution Then, the vegetable was sanitized with hydrogen peroxide $\left(0 ; 5 ; 10\right.$ and $\left.20 \mathrm{~mL} \mathrm{~L}^{-1}\right)$ for 10 minutes. The pathogens were monitored immediately after sanitization and after 4 days of storage at $10^{\circ} \mathrm{C}$. In other similar experiment, but without inoculation of pathogens, the snap bean were evaluated periodically. The surface color, $\mathrm{pH}$, activity of phenylalanine ammonia-lyase, peroxidase and polyphenoloxidase enzymes, chlorophyll and carotenoids contents were evaluated. The sanitization with hydrogen peroxide reduced the count of $E$. coli and S. enteritidis, being similar for different hydrogen peroxide concentrations. The browning of the section surface of snap bean was controlled by hydrogen peroxide in the concentration of $20 \mathrm{~mL} \mathrm{~L}^{-1}$. The activity of the enzymes as well as the pigments content (chlorophyll and carotenoids) were not affected by treatments, except the polyphenoloxidase enzyme. The $\mathrm{pH}$ increased during storage and was greatest in snap bean sanitized with $20 \mathrm{~mL} \mathrm{~L}^{-1}$. The sanitization with hydrogen peroxide is effective in reducing population of E.coli and S. enteritidis and minimizing browning in fresh cut snap bean, but caused spots on the vegetable skin, precluding its use.
\end{abstract}

Keywords: Phaseolus vulgaris L., microbiology, quality, sanitization. 


\section{Introdução}

O interesse por produtos minimamente processados tem sido cada vez maior. Pesquisa junto aos consumidores de hortaliças minimamente processadas indicou que estes consumidores buscam melhorar a qualidade nutricional das suas refeições, mas não tem tempo suficiente para o preparo total da alimentação, assim este tipo de processamento seria uma alternativa em termos de comodidade, praticidade, higiene e economia de tempo no preparo das refeições (Peres et al., 2008).

○ feijão-vagem (Phaseolus vulgaris L.), ou snap bean, também conhecido popularmente como vagem, é uma hortaliça que apresenta boa aceitação no Brasil, sendo produzida principalmente, por pequenos produtores e em todos os estados brasileiros. $O$ consumo principal é in natura, ou em conservas. Possui elevado teor de fibras alimentares $(2,4 \%)$, proteínas ( $1,8 \%)$, além de minerais como o cálcio (41 mg), manganês $(0,50 \mathrm{mg})$, fósforo (28 mg) e ferro $(0,4 \mathrm{mg})$ (TACO, 2011$)$.

Estudos preliminares para o processamento mínimo da vagem apresentam como principal defeito o escurecimento da superfície de corte (Peres etal., 2011). A destruição da compartimentação celular ocasionado pelo corte possibilita que enzimas como polifenoloxidase e substratos como polifenois entrem em contato e produzam reações de escurecimento (Limbo \& Piergiovanni, 2007; Rico et al., 2007).

A carga microbiana residual é outro fator de grande importância na qualidade e conservação de vegetais minimamente processados. Os processos de higienização reduzem, mas não exterminam todos os microorganismos e estes podem afetar adversamente a qualidade e a segurança desses produtos, considerando que patogênicos, podem compor a microbiota contaminante decorrente do manuseio a que são submetidos (Tresseler et al., 2009; Tomás-Callejas et al., 2012).

A RDC n 12 de 02 de Janeiro de 2001, da Agência Nacional de Vigilância Sanitária estabelece padrões microbiológicos para os produtos alimentícios comercializados no Brasil, para as hortaliças minimamente processadas preconiza a pesquisa de Salmonella sp. e coliformes a $45^{\circ} \mathrm{C}$ (Brasil, 2001).

Diversos sanitizantes têm sido utilizados para redução dos micro-organismos presentes nos vegetais. Dentre eles, o cloro, nas suas diversas formas, é o mais utilizado. No entanto a reação do cloro livre com a matéria orgânica pode formar trihalometanos, os quais têm sido conhecidos por seus efeitos carcinogênicos e mutagênicos (Artés et al., 2009).

Dentre os sanitizantes que não estão associados à formação de trihalometanos, há aqueles que além da atividade antimicrobiana minimizam reações de escurecimento como o peróxido de hidrogênio (Peng et al., 2008).

Dessa forma, este trabalho teve como objetivo avaliar a eficácia da sanitização com peróxido de hidrogênio em minimizar o escurecimento enzimático e reduzir patógenos em vagem minimamente processada.

\section{Material e métodos}

Efeito do peróxido de hidrogênio sobre a população de Escherichia coli e Salmonella enteritidis inoculadas em vagens minimamente processadas.

\section{Processamento das vagens}

As vagens (cultivar Itatiba II) foram selecionadas quanto à ausência de defeitos, resfriadas em câmara fria $110^{\circ} \mathrm{C}$ e UR $85 \pm 5 \%$ por 12h) e higienizadas. Posteriormente as extremidades das vagens foram cortadas manualmente, com faca de lâmina de inox. $\bigcirc$ corte foirealizado em fatias de aproximadamente $1 \mathrm{~cm}$ de comprimento utilizando processador de alimentos.

\section{Preparo da solução contaminante}

Cepas de E. coli ATCC 25922 provenientes da Coleção de Culturas Tropicais da Fundação André Tosello e de S. enteritidis ATCC 13076, isolada e identificada de amostras de fezes humanas do Lab. de Análises Clínicas da Universidade Sagrado Coração, mantidas sob refrigeração em tubos contendo ágar nutriente foram semeadas em caldo triptona e incubadas a $37^{\circ} \mathrm{C}$ por $24 \mathrm{~h}$ para ativação. Após esse período estriou-se a E. coli em placas com 
meio de cultura EMB (Eosina Azul de Metileno) e a $S$. enteritidis em placas com meio de cultura XLD (Xilose Lisina Desoxicolato). Após a incubação, as colônias foram confirmadas por meio de testes bioquímicos. Uma vez confirmada a pureza e a identidade das culturas, as mesmas foram semeadas em tubos inclinados contendo NA e incubadas a $37^{\circ} \mathrm{C}$ por $48 \mathrm{~h}$ para multiplicação da cepa. Após esse período a cultura foi adicionada em erlenmeyer contendo $90 \mathrm{~mL}$ de caldo lactosado a $1 \%$ e incubada a $37^{\circ} \mathrm{C}$ por $24 \mathrm{~h}$, quando $7 \mathrm{~mL}$ do inóculo foram transferidos para $200 \mathrm{~mL}$ de caldo com lactose.

\section{Contaminação das vagens}

As vagens minimamente processadas (75g) foram vertidas nas soluções contaminantes e mantidas por 10 minutos em agitador micro placas para assegurar a distribuição dos microorganismos.

Posteriormente, as vagens foram retiradas das soluções contaminantes com auxílio de uma peneira estéril, acondicionadas em béquer estéril e mantidas em câmara de fluxo laminar por 1 hora para secagem e aderência dos micro-organismos (Santos et al., 2010). Após a secagem, as vagens foram imersas nas soluções sanificantes de peróxido de hidrogênio $(5,10$ e 20 $\mathrm{mL} \mathrm{L}^{-1}$ ) e em água destilada, sendo mantidas por 10 minutos em agitador de microplacas. Vagens sem imersão foram utilizadas como controle.

Após a imersão em solução de peróxido de hidrogênio, o excesso de solução foi drenado e amostras de vagens foram armazenadas em B.O.D a $10 \pm 0,5^{\circ} \mathrm{C}$ por quatro dias.

O delineamento foi inteiramente ao acaso em esquema fatorial $5 \times 2$ ( 5 tratamentos e 2 períodos de avaliações), utilizando-se triplicata para cada uma das três diluições selecionadas.

\section{Avaliações}

A quantificação de S. enteritidis e E. coli nas vagens foi realizada imediatamente após aplicação dos tratamentos e aos quatro dias de armazenamento. Realizou-se plaqueamento em meio seletivo, utilizando-se método adaptado de Sagong et al. (2011).
Análise dos resultados

Os resultados expressos em log de Unidades Formadoras de Colônias (log UFC $\mathrm{g}^{-1}$ ) foram submetidos à análise de variância e as médias comparadas pelo teste de Tukey (5\%).

Os resultados do dia do processamento foram submetidos à análise de variância e as médias de tratamentos foram comparadas com o controle pelo teste bilateral de Dunnet (5\%), de modo a identificar se as reduções decimais (log de UFC da população inicial do tratamento controle - log UFC da população inicial das vagens tratadas) foram significativas. O programa estatístico utilizado foi o ASSISTAT 7.7 Beta.

Efeito do peróxido de hidrogênio sobre o escurecimento enzimático da superfície de corte de vagem minimamente processada

Vagens (cultivar Itatiba II) foram minimamente processadas conforme descrito no experimento anterior. Posteriormente foram enxaguadas em água destilada para eliminação do suco celular e em seguida imersas por dez minutos nas soluções de peróxido de hidrogênio $\left(5,10\right.$ e $\left.20 \mathrm{~mL} \mathrm{~L}^{-1}\right)$. Como controle foi utilizado água destilada.

Após a eliminação do excesso de água em centrífuga as vagens foram acondicionadas em bandeja de poliestireno $(14 \times 21 \mathrm{~cm})$ revestida por filme de PVC 20um (aproximadamente $250 \mathrm{~g}$ de produto minimamente processado por bandeja) e o armazenamento foi realizado durante sete dias em câmara fria a $10 \pm 1^{\circ} \mathrm{C}$ e UR $85 \pm 5 \%$, simulando temperatura média das gôndolas de supermercados.

O delineamento foi inteiramente casualizado em esquema fatorial $4 \times 3 / 4$ tratamentos $\times 3$ períodos de avaliações) para as características físico-químicas e fatorial $4 \times 4$ (4 tratamentos $\times 4$ períodos de avaliações) para os aspectos bioquímicos. Foram utilizadas três repetições. Cada repetição foi composta por uma bandeja contendo vagem minimamente processada.

As avaliações referentes às características físico-químicas foram realizadas no dia do processamento, no quarto e sétimo dia de armazenamento enquanto as avaliações bioquímicas foram realizadas no dia do 
processamento, no segundo, quarto e sétimo dia de armazenamento.

\section{Avaliações}

Características físico-químicas:

a) Coloração da superfície de corte e casca: Foram realizadas duas leituras, em lados opostos da superfície de corte e da casca, totalizando 60 leituras para cada repetição de cada tratamento. As leituras foram realizadas em colorímetro Minolta, modelo CR-400, com resultados expressos em ho (ângulo de cor hue).

b) $\mathrm{pH}: \mathrm{O} \mathrm{pH}$ do suco homogeneizado de vagem foi medido em pHmetro de bancada.

\section{Aspectos Bioquímicos}

As amostras foram congeladas em nitrogênio líquido, mantidas a $-80^{\circ} \mathrm{C}$ por aproximadamente 15 dias, quando foram preparados os extratos enzimáticos para as avaliações das atividades enzimáticas, e realizada a extração para as análises de clorofila e carotenoides.

\section{Obtenção do extrato enzimático}

Porções de vagem congeladas foram trituradas em moinho, pesadas em quantidade suficiente e homogeneizadas com solução tampão em gral de porcelana. A solução homogênea resultante foi centrifugada a $4^{\circ} \mathrm{C}$. O sobrenadante foi coletado, constituindo então os extratos enzimáticos, os quais foram utilizados para a determinação das atividades enzimáticas.

Fenilalanina amônia-liase (PAL) (EC 4.3.1.5): Foi realizada conforme metodologia de Peixoto et al. (1999). Os resultados foram expressos em $\mu$ moles min $^{-1}$.

Peroxidase (POD) (EC 1.11.1.7): Foi determinada conforme método descrito por Lima (1994). Os resultados foram expressos em $\mu$ Moles de $\mathrm{H}_{2} \mathrm{O}_{2}$ decomposto $\mathrm{min}^{-1} \mathrm{~g}^{-1}$.

Polifenoloxidase (PPO) (EC 1.14.18.1) Foi realizada conforme metodologia descrita por Cano et al. (1997). Os resultados foram expressos em $\mu$ moles de catecol transformado/min/g.

\section{Clorofila e Carotenoides}

Para os teores de clorofila e carotenoides a extração foi feita utilizando-se o método de Arnon (1949). Os cálculos foram feitos segundo Lichtenthaler (1987). Os teores de clorofila e carotenoides foram expressos em $\mu \mathrm{g}$ por grama de tecido fresco.

\section{Análise dos resultados}

Os dados obtidos foram submetidos à análise de variância e as médias comparadas pelo teste de Tukey (5\%). O programa estatístico utilizado foi o ASSISTAT 7.7 Beta.

\section{Resultados e discussão}

1) Efeito do peróxido de hidrogênio sobre a população de E. coli e S. enteritidis inoculadas em vagens minimamente processadas

A população de E. coli das vagens minimamente processadas foi reduzida pelo peróxido de hidrogênio, sendo que as reduções decimais para as vagens sanitizadas com $5 \mathrm{~mL}$ $\mathrm{L}^{-1} ; 10 \mathrm{~mL} \mathrm{~L}^{-1}$ e $20 \mathrm{~mL} \mathrm{~L}^{-1}$ foram maiores que 1 ciclo log e nas vagens que foram apenas imersas em água a redução $(0,35)$ (Tabela 1) foi devido à sua ação mecânica.

Tabela 1. Contagem e número de reduções decimais de E. coli ATCC 25922 em vagens minimamente processadas sanificadas com peróxido de hidrogênio $\left(\mathrm{H}_{2} \mathrm{O}_{2}\right)$ e armazenadas a $10^{\circ} \mathrm{C}$

\begin{tabular}{|c|c|c|c|c|}
\hline \multirow[t]{2}{*}{ Tratamentos } & \multicolumn{2}{|c|}{ E. coli (log UFC.g $\left.{ }^{-1}\right)$} & \multicolumn{2}{|c|}{ Reduções* } \\
\hline & Dia 0 & Dia 4 & ${ }^{* 1}$ & ${ }^{*} 2$ \\
\hline Controle & $6,35 \mathrm{aA}$ & $5,21 \mathrm{aB}$ & & $1,14^{*}$ \\
\hline $\mathrm{H}_{2} \mathrm{O}$ & $6,00 \mathrm{bA}$ & $4,65 \mathrm{bB}$ & $0,35^{*}$ & $1,35^{*}$ \\
\hline $\mathrm{H}_{2} \mathrm{O}_{2} 5 \mathrm{~mL} \mathrm{~L}^{-1}$ & $5,13 \mathrm{CA}$ & $3,05 \mathrm{CB}$ & $1,22^{*}$ & $2,08^{*}$ \\
\hline $\mathrm{H}_{2} \mathrm{O}_{2} 10 \mathrm{~mL} \mathrm{~L}^{-1}$ & $5,01 \mathrm{cA}$ & $2,95 \mathrm{CB}$ & $1,34^{*}$ & $2,06^{*}$ \\
\hline $\mathrm{H}_{2} \mathrm{O}_{2} 20 \mathrm{~mL} \mathrm{~L}^{-1}$ & $5,05 \mathrm{cA}$ & $2,46 \mathrm{~dB}$ & $1,30 *$ & $2,53^{*}$ \\
\hline
\end{tabular}

Células viáveis da solução contaminante 7,25 (log UFC.mL-1). Médias seguidas de mesma letra minúscula na coluna e maiúscula na linha não diferem entre si pelo teste de Tukey (5\%). *1. Reduções obtidas no dia 0 (imediatamente após a sanificação) em relação ao controle, sendo: diferem do controle pelo teste de Dunnet (5\%); ns não diferem do controle pelo teste de Dunnet (5\%) *2. Reduções obtidas no dia 4 em relação ao dia 0 , sendo * redução significativa pelo teste de Tukey $(5 \%)$; ns redução não significativa pelo teste de Tukey (5\%) 
Back et al. (2014) avaliaram a eficácia de vapor de peróxido de hidrogênio nas concentrações $(0 ; 1 ; 3 ; 5$; e $10 \%)$ e tempos de tratamento (0;2;4;6;8 e 10 min.) na redução de $S$. typhimurium, E. coli O 157:H7 e L. monocytogenes em alfaces. Os autores observaram que a vaporização a $10 \%$ por 10 minutos foi a mais efetiva. A redução nos níveis de S. Typhimurium, E. coli O 157:H7 e L. monocytogenes nas alfaces foi de 3,12; 3,15 e 2,95 UFC $\mathrm{g}^{-1}$, respectivamente. No decorrer do armazenamento a população de E. coli das vagens sanitizadas continuou reduzindo, isso mostra que o peróxido de hidrogênio teve ação residual. As reduções nas vagens dos tratamentos $5 \mathrm{~mL} \mathrm{~L}^{-1}, 10 \mathrm{~mL} \mathrm{~L}^{-1}$ e 20 $\mathrm{mL} \mathrm{L}^{-1}$ foram maiores que 2 ciclos log (Tabela 1).

As vagens controle e aquelas apenas imersas em água também apresentaram redução decimal em relação à população de E. coli ao longo do armazenamento, sendo esta redução de 1,14 e 1,35, respectivamente (Tabela 1). Resultados similares foram relatados por UkUku et al. (2001) em melões inoculados com E. coli e não sanitizados.

A redução de população de $E$. coli nas vagens controle e apenas imersas em água é explicada pela existência de outros microorganismos que podem se multiplicar e produzir substâncias que inibem o desenvolvimento da $E$. coli, como por exemplo, o ácido láctico. Segundo Jay (2005) os lactobacilos são encontrados em todos ou quase em todos os vegetais junto com outras bactérias produtoras de ácido láctico.

Pesquisas realizadas por Costa et al. (2012) relatam que bactérias L. acidophilus LA5, L. plantarum DCTA 8420 e B. lactis DCTA 8724 apresentaram capacidade de inibição para E. coli ATCC 25922. Pereira \& Gómez (2007) relataram em seu trabalho a inibição de E. coli e S. aureus por L. acidophilus enquanto Lahtinen et al. (2007) observaram inibição de S. aureus, Salmonella spp. e E. coli por linhagens de Bifidobacterium.

A ação do peróxido de hidrogênio em reduzir a população de $S$. enteritidis foi positiva, apresentando redução decimal acima de dois ciclos log, mas não apresentou efeito residual, ou seja, a redução ocorreu apenas após a sanificação, sendo semelhante nas diferentes concentrações de peróxido estudadas. A redução observada nas vagens apenas imersas em água $(1,15)$ foi devido à sua ação mecânica (Tabela 2).

Tabela 2. Contagem e número de reduções decimais de Salmonella enteritidis ATCC 13076 em vagens minimamente processadas sanificadas com peróxido de hidrogênio $\left(\mathrm{H}_{2} \mathrm{O}_{2}\right)$ e armazenadas a $10^{\circ} \mathrm{C}$

\begin{tabular}{|c|c|c|c|c|}
\hline \multirow{2}{*}{ Tratamentos } & \multicolumn{2}{|c|}{ S. enteritidis (log UFC g $\left.{ }^{-1}\right)$} & \multicolumn{2}{|c|}{ Reduções* } \\
\hline & Dia 0 & Dia 4 & $* 1$ & $* 2$ \\
\hline Controle & $5,59 \mathrm{aA}$ & $5,54 \mathrm{aA}$ & & $0,07 \mathrm{~ns}$ \\
\hline $\mathrm{H}_{2} \mathrm{O}$ & $4,80 \mathrm{bA}$ & $4,81 \mathrm{bA}$ & $1,15^{*}$ & $-0,39 \mathrm{~ns}$ \\
\hline $\mathrm{H}_{2} \mathrm{O}_{2} 5 \mathrm{~mL} \mathrm{~L}^{-1}$ & $3,29 \mathrm{CB}$ & $4,20 \mathrm{cA}$ & $2,31^{*}$ & $-0,98 *$ \\
\hline $\mathrm{H}_{2} \mathrm{O}_{2} 10 \mathrm{~mL} \mathrm{~L}^{-1}$ & $3,44 \mathrm{CB}$ & $3,94 \mathrm{cA}$ & $2,25^{*}$ & $-0,58 *$ \\
\hline $\mathrm{H}_{2} \mathrm{O}_{2} 20 \mathrm{~mL} \mathrm{~L}^{-1}$ & $3,30 \mathrm{cA}$ & $3,30 \mathrm{dA}$ & $2,31^{*}$ & $-0,02 \mathrm{~ns}$ \\
\hline
\end{tabular}

Células viáveis da solução contaminante 7,40 (log UFC.mL-1) . Médias seguidas de mesma letra minúscula na coluna e maiúscula na linha não diferem entre si pelo teste de Tukey (5\%). *1. Reduções obtidas no dia 0 (imediatamente após a sanificação) em relação ao controle, sendo: * diferem do controle pelo teste de Dunnet (5\%); ns não diferem do controle pelo teste de Dunnet (5\%). *2. Reduções obtidas no dia 4 em relação ao dia 0 , sendo * diferem do controle pelo teste de Tukey (5\%); ns não diferem do controle pelo teste de Tukey (5\%)

Abadias et al. (2011) observaram redução acima de 2,5 ciclos log em maçã minimamente processadas inoculadas com Salmonella e armazenadas a $10^{\circ} \mathrm{C}$. Os autores testaram concentrações de 5, 10 e $20 \mathrm{~mL} \mathrm{~L}^{-1}$ e observaram que a concentração de $20 \mathrm{~mL} \mathrm{~L}^{-1}$ foi mais efetiva.

A sanificação em pimentão, morango e agrião com peróxido de hidrogênio (5\%) promoveu elevada redução nos níveis microbiológicos desses produtos. Por outro lado, peróxido $1 \%$ teve baixo impacto, mas foi mais efetivo que a água (Alexandre et al., 2012).

2) Efeito do peróxido de hidrogênio sobre o escurecimento enzimático da superfície de corte e a qualidade microbiológica de vagem minimamente processada

No dia do processamento (dia 0), todos os tratamentos diferiram entre si $(P<0,05)$ em relação à cor da casca representada pelo ângulo de cor hue (hº (Tabela 3), sendo 
que todas as concentrações de peróxido de hidrogênio testadas mancharam a casca das vagens. As vagens tratadas com peróxido $5 \mathrm{~mL} \mathrm{~L}^{-1}$ apresentaram manchas de menor intensidade. Quanto maior a concentração do peróxido de hidrogênio, maior foi a intensidade das manchas.

Imediatamente após a sanificação, observou-se que a coloração da casca alterou para um tom de verde mais claro e com manchas amarronzadas causando redução nos valores do ângulo de cor hue, as quais desapareceram ou reduziram em tempos diferentes, conforme o tratamento, sendo observado aumento dos valores de $\mathrm{h}^{\circ}$ (Figura 1). As manchas das cascas das vagens tratadas com $5 \mathrm{~mL} \mathrm{~L}^{-1}$ de peróxido desapareceram seis horas após a sanificação. Já as manchas das vagens tratadas $10 \mathrm{~mL} \mathrm{~L}^{-1} \mathrm{e}$ $20 \mathrm{~mL} \mathrm{~L}^{-1}$ de peróxido reduziram depois de 8 horas após o processamento, porém as manchas ainda persistiam.

O escurecimento enzimático ocorre quando os produtos do metabolismo dos fenilpropanóides, como os compostos fenólicos e possivelmente outros substratos, são oxidados em reações catalisadas por fenolases, como as polifenoloxidases (PPO) e peroxidases (POD) (VILAS BOAS et al.,2007; SILVA et al, 2011). Os compostos fenólicos são primeiramente convertidos para compostos secundários chamados de quinonas sendo possível reverter a reação neste estágio. No entanto, caso a reação se desenvolva, as quinonas envolvemse em uma série de reações químicas e formam melaninas, pigmentos da cor marrom (O'BEIRNE, 2001).

O escurecimento da casca observado logo após a sanificação com o peróxido de hidrogênio, deve-se provavelmente à ação da enzima POD, pois segundo Fernandes et al. (2010), as peroxidases (POD) têm atividade típica na reação de oxidação de compostos fenólicos em presença de peróxido de hidrogênio e são obtidas quinonas como produto.

A redução do escurecimento enzimático observado após seis horas no tratamento com 5 $\mathrm{mL} \mathrm{L}^{-1}$ de peróxido e oito horas nos tratamentos com 10 e $20 \mathrm{~mL} \mathrm{~L}^{-1}$ de peróxido, deve, provavelmente, ao fato reversão das quinonas novamente a compostos fenólicos, como citado anteriormente.

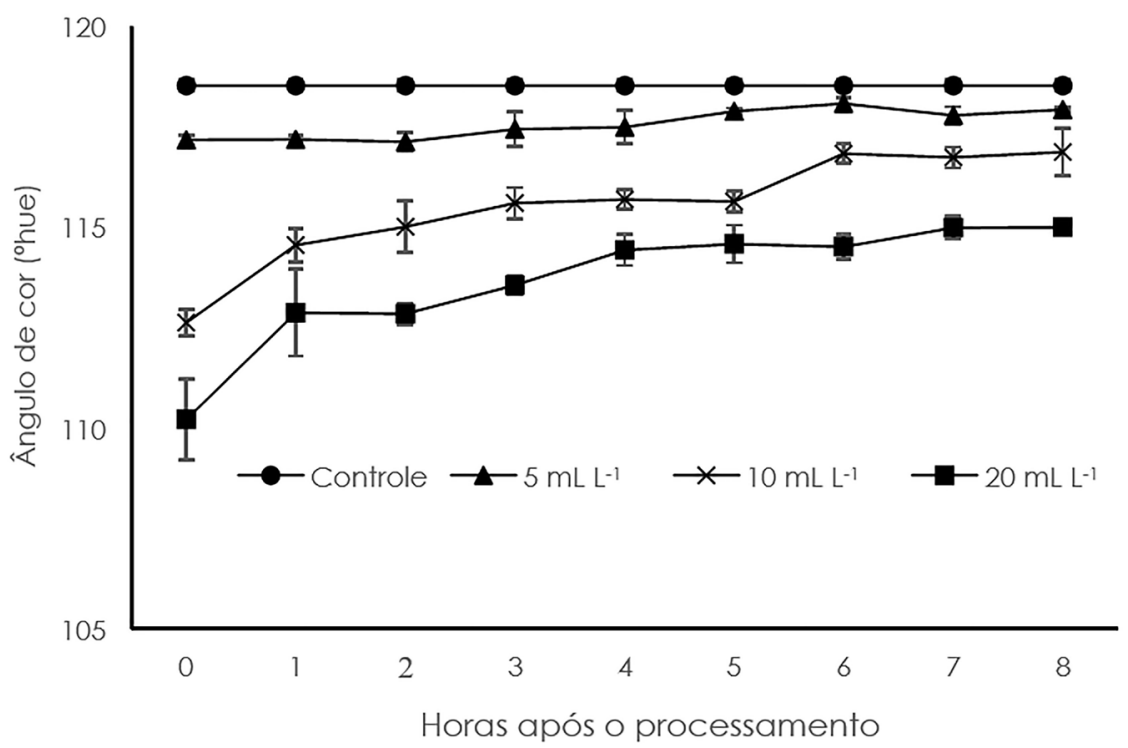

Figura 1. Coloração da casca das vagens minimamente processadas sanificadas com peróxido de hidrogênio e armazenadas a $10^{\circ} \mathrm{C}$. As barras verticais representam o desvio padrão da média

Ao longo do armazenamento os tratamentos com peróxido nas concentrações de 10 e $20 \mathrm{~mL} \mathrm{~L}^{-1}$ apresentaram aumento dos valores do ângulo de cor hue (Tabela 3). Esse aumento dos valores de $h^{\circ}$ deve-se à redução das manchas pela provável reversão das quinonas em compostos fenólicos.

As vagens tratadas com $5 \mathrm{~mL} \mathrm{~L}^{-1}$ de peróxido assemelharam-se ao controle, mantendo valores constantes, ao longo de todo o período de armazenamento, devido

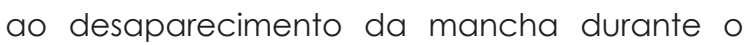


armazenamento (Tabela 3).

Tabela 3. Coloração da casca ( ${ }^{\circ}$ hue) das vagens minimamente processadas sanificadas com peróxido de hidrogênio $\left(\mathrm{H}_{2} \mathrm{O}_{2}\right)$ e armazenadas a $10^{\circ} \mathrm{C}$

\begin{tabular}{|c|c|c|c|c|}
\hline \multirow{2}{*}{ Tratamentos } & \multicolumn{3}{|c|}{ Dias de armazenamento } & \multirow[b]{2}{*}{ Médias } \\
\hline & $0^{1}$ & 4 & 7 & \\
\hline Controle & $118,52 \mathrm{Aa}$ & $118,17 \mathrm{ABa}$ & $117,38 \mathrm{Ba}$ & $118,03 a$ \\
\hline $\mathrm{H}_{2} \mathrm{O}_{2} 5 \mathrm{~mL} \mathrm{~L}^{-1}$ & $117,16 \mathrm{Ab}$ & $117,77 \mathrm{Aa}$ & $117,47 \mathrm{Aa}$ & $117,47 a$ \\
\hline $\mathrm{H}_{2} \mathrm{O}_{2} 10 \mathrm{~mL} \mathrm{~L}^{-1}$ & $112,62 \mathrm{BC}$ & $116,34 \mathrm{Ab}$ & $115,95 \mathrm{Ab}$ & $114,97 \mathrm{~b}$ \\
\hline $\mathrm{H}_{2}^{2} \mathrm{O}_{2}^{2} 20 \mathrm{~mL} \mathrm{~L}^{-1}$ & $110,21 \mathrm{Bd}$ & $115,28 \mathrm{AC}$ & $115,96 \mathrm{Ab}$ & $113,81 \mathrm{C}$ \\
\hline Médias & $114,63 B$ & $116,89 \mathrm{~A}$ & $116,69 \mathrm{~A}$ & \\
\hline
\end{tabular}

Ao contrário do que ocorreu na casca, observou-se que o peróxido de hidrogênio minimizou o escurecimento na superfície do corte, sendo observada uma correlação inversa entre o aumento da concentração de peróxido e a redução nos valores de do ângulo hue. No quarto dia de armazenamento as vagens tratadas com $10 \mathrm{~mL} \mathrm{~L}^{-1}$ e $20 \mathrm{~mL} \mathrm{~L}^{-1}$ apresentaram menor escurecimento em relação às vagens apenas imersas em água (Tabela 4).

No sétimo dia de armazenamento, o peróxido na concentração $20 \mathrm{~mL} \mathrm{~L}^{-1}$ se mostrou mais eficiente em minimizar 0 escurecimento na superfície de corte que o $10 \mathrm{~mL} \mathrm{~L}^{-1}$. As vagens do tratamento controle e peróxido $5 \mathrm{~mL} \mathrm{~L} \mathrm{~L}^{-1}$ apresentaram menor ângulo de cor hue ( $\left.{ }^{\circ} \mathrm{h}\right)$ e consequentemente maior escurecimento (Tabela 4).

Tabela 4. Coloração da superfície de corte $\left({ }^{\circ} \mathrm{h} u e\right)$ das vagens minimamente processadas sanificadas com peróxido de hidrogênio $\left(\mathrm{H}_{2} \mathrm{O}_{2}\right)$ e armazenadas a $10^{\circ} \mathrm{C}$

\begin{tabular}{ccccc}
\hline \multirow{2}{*}{ Tratamentos } & \multicolumn{4}{c}{ Dias de armazenamento } \\
\cline { 2 - 5 } & $0^{1}$ & 4 & 7 & Médias \\
\hline Controle & $117,94 \mathrm{Aa}$ & $115,89 \mathrm{Bb}$ & $112,65 \mathrm{Cc}$ & $115,50 \mathrm{C}$ \\
$\mathrm{H}_{2} \mathrm{O}_{2} 5 \mathrm{~mL} \mathrm{~L}^{-1}$ & $117,94 \mathrm{Aa}$ & $116,79 \mathrm{Bab}$ & $113,50 \mathrm{Cc}$ & $116,08 \mathrm{bc}$ \\
$\mathrm{H}_{2} \mathrm{O}_{2} 10 \mathrm{~mL} \mathrm{~L}^{-1}$ & $117,94 \mathrm{Aa}$ & $117,13 \mathrm{Aa}$ & $114,79 \mathrm{Bb}$ & $116,62 \mathrm{ab}$ \\
$\mathrm{H}_{2} \mathrm{O}_{2} 20 \mathrm{~mL} \mathrm{~L}^{-1}$ & $117,94 \mathrm{Aa}$ & $117,19 \mathrm{Aa}$ & $116,02 \mathrm{Ba}$ & $117,05 \mathrm{a}$ \\
\hline Médias & $117,94 \mathrm{~A}$ & $116,75 \mathrm{~B}$ & $114,24 \mathrm{C}$ & \\
\hline
\end{tabular}

Emcastanhas minimamente processadas tratadas com peróxido de hidrogênio $(0,15 ; 0,3$; $0,6$ e $0,9 \%)$ por um minuto seguido de enxague por dois minutos também foi observado redução do índice de escurecimento (Peng et al., 2008), porém segundo os autores o mecanismo pelo qual o peróxido de hidrogênio retarda o escurecimento não está totalmente esclarecido.

\section{Atividade enzimática}

De acordo com a análise de variância a atividade da PAL não foi afetada pelos tratamentos e nem pelo tempo de armazenamento. A atividade dessa enzima foi muito baixa, com valores menores que $0,1 \mu$ moles.

A análise de variância demonstrou que a atividade da POD não foi afetada pelos tratamentos, mas sim pelo tempo de armazenamento. Essa enzima apresentou pico na atividade no segundo dia de armazenamento, indicando consumo dos substratos (Figura 2).

A peroxidase catalisa a redução de peróxidos por meio de um mecanismo complexo de reações (Uliana et al., 2008), tendo como alguns desses produtos as melaninas, compostos que conferem cor escura aos tecidos.

Em castanhas a atividade da peroxidase foi menor quanto maior a concentração de peróxido, a qual variou de 0,15 a 0,9\% (Peng et al. 2008). Na presente pesquisa as concentrações de peróxido utilizadas correspondem a 0,$5 ; 1$ e $2 \%$, porém a atividade da enzima não foi afetada, mas houve minimização do escurecimento da superfície de corte (Tabela 3). Esses resultados podem estar relacionados com 0 material vegetal (genótipo), principalmente com 0 
tipo de compostos fenólicos existente, os quais

podem ser oxidados por múltiplos processos.

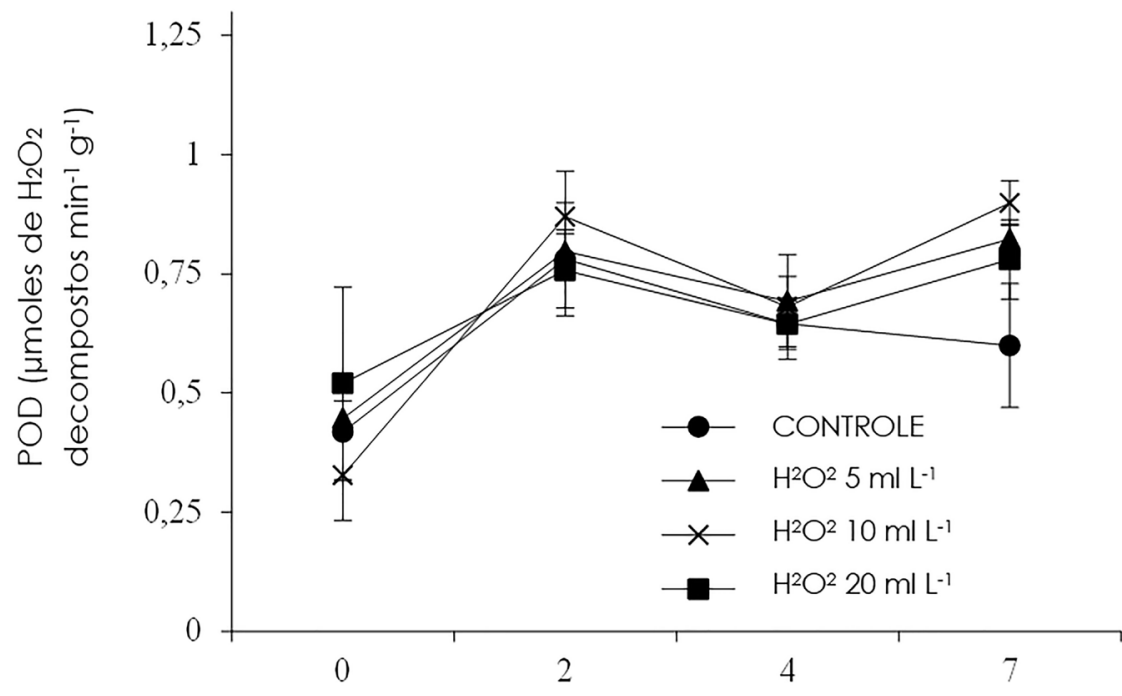

Dias de armazenamento

Figura 2. Atividade da enzima Peroxidase (POD) em vagem minimamente sanificada com peróxido de hidrogênio $\left(\mathrm{H}^{2} \mathrm{O}^{2}\right)$ e armazenadas a $10^{\circ} \mathrm{C}$. As barras verticais representam o desvio padrão da média.

De acordo com a análise de variância a atividade da PPO foi afetada pelos tratamentos, pelo tempo de armazenamento e houve interação. As vagens tratadas com peróxido de hidrogênio na concentração de $10 \mathrm{~mL} . \mathrm{L}^{-}$ ' apresentaram menor atividade da PPO imediatamente após o processamento em relação às vagens controle (apenas enxaguadas em água) (Figura 3).

No entanto esse comportamento não perdurou ao longo do armazenamento e a atividade enzimática das vagens tratadas assemelhou-se ao controle, indicando que o peróxido de hidrogênio não retarda atividade da enzima, apesar de minimizar o escurecimento da superfície de corte.

O maior escurecimento observado na região do corte dos tratamentos controle e $5 \mathrm{~mL}$ $\mathrm{L}^{-1}$ de peróxido (Tabela 4), pode, provavelmente - ser resultado da maior atividade da enzima PPO no segundo dia de armazenamento.

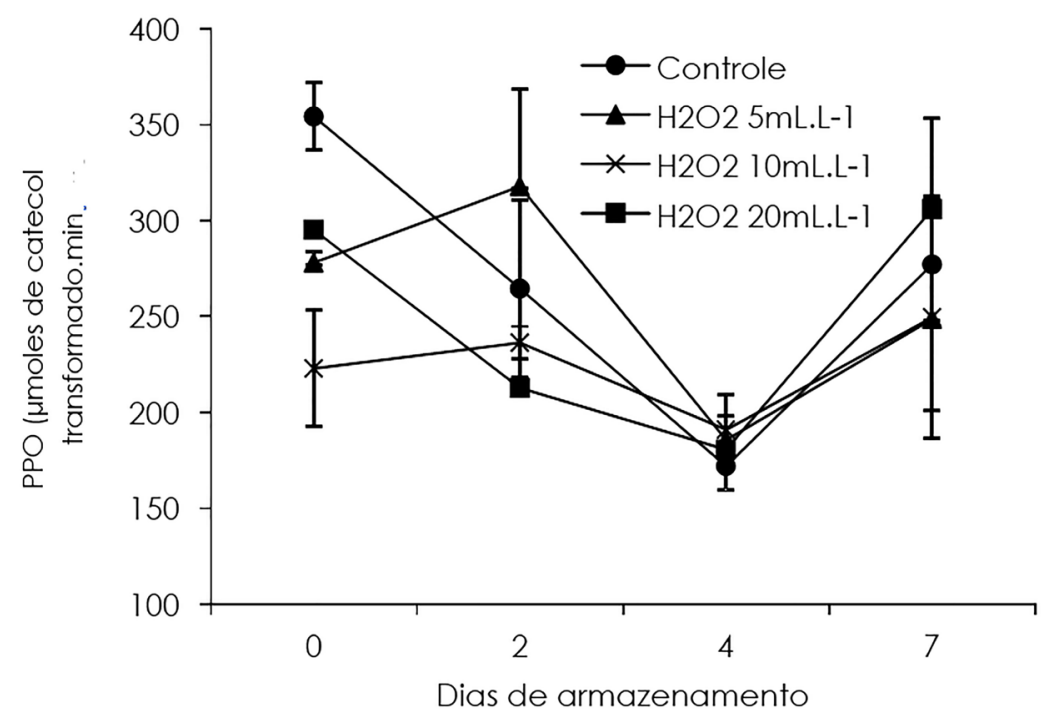

Figura 3. Atividade da enzima Polifenoloxidase (PPO) em vagem minimamente processada sanificada com peróxido de hidrogênio $\left(\mathrm{H}_{2} \mathrm{O}_{2}\right)$ e armazenada a $10^{\circ} \mathrm{C}$. As barras verticais representam o desvio padrão da média 
$\mathrm{pH}$

$\mathrm{O} \mathrm{pH}$ das vagens foi influenciado pelos tratamentos e pelo tempo de armazenamento. As vagens tratadas com $20 \mathrm{~mL} \mathrm{~L}^{-1}$ apresentaram maior $\mathrm{pH}$ em relação aquelas enxaguadas somente em água. $\mathrm{O} \mathrm{pH}$ das vagens de todos os tratamentos aumentou no quarto dia, mantendo-se até $\mathrm{O}$ final do armazenamento. O valor médio de $\mathrm{pH}$ aumentou de 5,93 no dia do processamento para 6,5 a partir do quarto dia de armazenamento. Em mandioquinhasalsa a sanificação com peróxido de hidrogênio não afetou o pH (Nunes et al., 2010). Rinaldi et al. (2009) também observaram aumento do $\mathrm{pH}$ durante $\mathrm{O}$ armazenamento de repolho minimamente processado. Um dos fatores que leva ao aumento de $\mathrm{pH}$ refere-se à proliferação dos vegetais por micro-organismos Gram negativos, o que pode resultar na quebra de proteínas, com a liberação de compostos básicos (Jacxsens et al., 2003).

\section{Clorofila e Carotenoides}

Pela análise de variância observouse que não houve efeito dos tratamentos com peróxido de hidrogênio e nem do tempo de armazenamento sobre os teores de clorofila e carotenoides. Isso demonstra que o peróxido não interferiu nesses pigmentos, embora tenha sido verificado intensa mudança de coloração da casca das vagens após aplicação dos tratamentos. O teor médio de clorofila foi 0,08 $\mathrm{mg} \mathrm{g}^{-1}$ de matéria fresca e o de carotenoide 0,6 $\mathrm{mg} \mathrm{g}^{-1}$ de matéria fresca.

Resultados contrários foram relatados em morangos tratados com peróxido de hidrogênio (5\%), em que houve redução no conteúdo de carotenoides, o que proporcionou impacto negativo na coloração do produto (Alexandre et al., 2012).

\section{Conclusões}

A sanificação com peróxido de hidrogênio nas concentrações $(5,10$ e $20 \mathrm{~mL}$ $\mathrm{L}^{-1}$ ) é eficaz em reduzir a população de E.coli e S. enteritidis enquanto a sanificação com peróxido na concentração de $20 \mathrm{~mL} \mathrm{~L}^{-1}$ é eficaz em minimizar o escurecimento na superfície de corte da vagem, porém ocasiona manchas na casca das vagens minimamente processadas, inviabilizando sua utilização.

\section{Agradecimentos}

À FAPESP (Processo 2011/08421-0) pelo auxílio financeiro. Ao CNPa pela Bolsa DT (Processo 310396/2011-5).

\section{Referências}

Abadias, M., Alegre, I., Usall, J.; Torres, R., Viñas, I. 2011. Evaluation of alternative sanitizers to chlorine disinfection for reducing foodborne pathogens in fresh-cut apple. Postharvest Biology and Technology, 59: 289-297.

Alexandre, E.M.C., Brandão, T.R.S., Silva, C.L.M. 2012. Assessment of the impacto $f$ hydrogen peroxide solutions on microbial loads and quality factors of red bell peppers, strawberries and watercress. Food Control, 27: 362-368.

Arnon, D.I. 1949. Copper enzymes in isolated chloroplasts: Polyphenol oxidases in Beta vulgaris. Plant Physiology, 24: 1-15.

Artés, F., Gómez, P., Aguayo, E., Escalona, V., Artés-Hernández, F. 2009. Sustainable sanitation techniques for keeping quality and safety of fresh-cut plant commodities. Postharvest Biology and Technology, 51: 287-296.

Back, K.H., HA, J.W., KANG, D.H. 2014. Effect of hydrogen peroxide vapor treatment for inactivating Salmonella Typhimurium, Escherichia coli O157:H7 and Listeria monocytogenes on organic fresh lettuce. Food Control, 44: 78-85.

Brasil. Resolução RDC n. 12 de 02 de janeiro de 2001 da Agência Nacional de Vigilância Sanitária. Dispõe sobre o Regulamento técnico sobre padrões microbiológicos para alimentos. Diário Oficial da República Federativa do Brasil, Brasília, DF, 10 de jan. 2001.

Cano, M.P., Ancos, O.B., Matallana, M.C., Cámara, M., Reglero, G., Tabera, J. 1997. Differences among spanish and latinamerican banana cultivars: morphological, chemical and sensory characteristics. Food Chemistry, 59: 411419.

Costa, N.G., Suguimoto, H.H., Miglioranza, L.H.S., Gómez, R.J.H. 2012. Atividade antimicrobiana de Lactobacillus e Bifodobacterium frente a microorganismos "in vitro". Semina: Ciência Agrárias, 33: 1839-1846.

Fernandes, P.L de O.; Silva, L.T.; Fontes, L. de O.; Rodrigues, A.P.m. dos S.; Ferreira, R.M. de A. 2010. Escurecimento enzimático em vegetais minimamente processados e seus métodos de controle. Revista Verde de Agroecologia e 
Desenvolvimento Sustentável, 5: 21-27.

Jacxsens, L., Devlieghere, F., Ragaert, P., Vanneste, E., Debevere, J. 2003. Relation between microbiological quality, metabolite production and sensory quality of equilibrium modified atmosphere packaged fresh cut produce. International Journal of Food Microbiology 83: 263-280.

Jay, J.M. 2005. Microbiologia de Alimentos. Artmed, Porto Alegre, Brasil. $711 \mathrm{p}$.

Lahtinen, S. J., Jalonen, L., Ouwehand, A. C., Salminen, S. J. 2007. Specific Bifidobacterium strains isolated from elderly subjects inhibit growth of Staphylococcus aureus. International Journal of Food Microbiology, 117: 125-128.

Lichtenthaler, H.K. 1987. Chlorophylls and carotenoids: pigments of photosynthetic biomembranes. In: Packer, L., Douce, R. (ed.). Methods in enzymology. Academic Press, New York, USA. p. 350-382.

Lima, G.P.P. 1994. Efeito do cálcio sobre o teor de poliaminas e atividade da peroxidase do nitrato em calos de arroz (Oriza sativa L. cv. IAC 4440). 85 p. (Tese de Doutorado) - Universidade Estadual Paulista, Botucatu, Brasil.

Limbo, S., Piergiovanni, L. Minimally processing potatoes: Part 2. 2007. Effects of high oxygen partial pressures in combination with ascorbic and citric acid on loss of some quality traits. Postharvest Biology and Technology, 43: 221-229.

Nunes, E.E., Vilas Boas, E.V.B., Xisto, A.L.R.P., Leme, S.C., Botelho, M.C. 2010. Avaliação de diferentes sanificantes na qualidade microbiológica de mandioquinha-salsa minimamente processada. Ciência e Agrotecnologia, 34: 990-994.

O'Beirne, D. 2001. Advances in sulphitereplacement technologies for fresh-cut produce. In: Second International Conference on FreshCut Produce. Gloucestershire, UK. Conference Proceedings. Campden \& Chorleywood Food. p.13-14.

Peixoto, P.H.P., Cambraia, J., Sant'anna, R., Mosquim, P.R., Moreira, M.A. 1999. Aluminium effects on lipid peroxidation and the actives of enzymes of oxidative metabolism in sorghum. Revista Brasileira de Fisiologia Vegetal, 11:137143.

Peng, L., Yang, S., Li, Q., Jiang, Y., Joyce, D. 2008. Hydrogen peroxide treatments inhibit the browing of fresh-cut Chinese water chestnut. Postharvest Biology and Technology, 47: 260-266.

Peres, J.E., Arruda, M.C.de., Fileti, M.S., Fischer, I.H., Simionato, E.M.R.S., Voltan, D.S. 2011. Qualidade de feijão-vagem minimamente processado em função das operações de enxague e sanificação. Semina, Ciências Agrárias, 32: 173180.

Perez, R., Ramos, A. M., Binoti, M. L., Sousa, P. H. M., Machado, G. M., \& Cruz, I. B. 2008. Perfil dos consumidores de hortaliças minimamente processadas de Belo Horizonte. Horticultura Brasileira, 26: 441-446.

Pereira, V. G., Gómez, R. J. H. C. 2007. Atividade antimicrobiana de Lactobacillus acidophilus, contra micro-organismos patogênicos veiculados por alimentos. Semina: Ciências Agrárias, 28: 229- 240.

Rico, D., Martin-DIANA, A.B., Barat, J.M., BarryRyan, C. 2007. Extending and measuring the quality of fresh cut fruit and vegetables: A review. Trends in Food Science and Technology, 18: 373386.

Rinaldi M.M., Benedetti B.C., Sarantópoulos, C.I.G.L., Moretti, C.L. 2009. Estabilidade de repolho minimamente processado sob diferentes sistemas de embalagem. Ciência e Tecnologia de Alimentos, 29: 310-315.

Sagong, H.G., Lee, S.Y., Chang, P.S., Heu, S., Ryu, S., Choi, Y.J., Kang, D.H. 2011. Combined effect of ultrasound and organic acids to reduce Escherichia coli 0157:H7, Salmonella Typhimurium, and Listeria monocytogenes on organic fresh lettuce. International Journal of Food Microbiology, 145: 287-292.

Santos, Y.O., Almeida, R.C.C., Guimarães, A.G., Almeida, P.F. 2010. Hygienic-sanitary quality of vegetables and evaluation of treatments for the elimination of indigenous $E$. coli and E. coli 0157:H7 from the surface of leaves of lettuce (Lactuca sativa L.). Ciência e Tecnologia de Alimentos, 30: 1083-1089.

Silva, E. de O.; Pinto, P.M.; Jacomino, A.P.; Silva, L.T. 2011. Processamento mínimo de produtos hortifrutícolas. Fortaleza: Embrapa Agroindústria Tropical. 72p. (Documentos 139).

Taco. Tabela Brasileira de Composição de Alimentos. 4ed. revisada e ampliada.

Campinas, SP: UNICAMP, 2011. Disponível em http://www.unicamp.br/nepa/taco/ contar/taco_4_edicao_ampliada_e_revisada. pdf? arquivo=†aco_4_versao_ampliada_e_ revisada.pdf. Acesso em 29 de janeiro de 2016.

Tomás-Callejas, A., López-Gálvez, F., Sbodio, A., Artés, F., Artés-Hernández, F., Suslow, T.V. 2012. Chlorine dioxide and chlorine effectiveness to prevent Escherichia coli O157:H7 and Salmonella croos-contamination on fresh-cut Red chard. Food Control, 23: 325-332. 
Palharini et al. (2017) / Peróxido de hidrogênio no controle...

Tresseler, J.F.M., Figueiredo, E.A.T.de., Figueiredo, R.W., Machado, T.F., Delfino, C.M., Souza, P.H.M.de. 2009. Avaliação da qualidade microbiológica de hortaliças minimamente processadas. Ciência e Agrotecnologia, 33: 1722-1727.

Uliana, C.V., Riccardi, C.S., Yamanaka, H. 2008. Estudo do comportamento eletroquímico da enzima peroxidase na presença de peróxido de hidrogênio e ácido 5-Aminossalicílico. Eclética Química, 33: 57-62.

Ukuku, D.O., Pilizota, V., \& Sapers, G.M. 2001. Influence of washing treatment on native microflora and Escherichia coli population of inoculated cantaloupes. Journal of Food Safety, 21: 31-47.

Vilas-Boas, E. V. B.; Vilas-Boas, B. M.; Giannoni, J. A.; Rosane, J. M. 2007. Tendências na área de processamento mínimo de frutas e hortaliças: avanços tecnológicos. In: SIMPÓSIO BRASILEIRO DE PÓS-COLHEITA: FRUTAS, HORTALIÇAS E FLORES, 2., 2007, Viçosa. Palestras e Resumos. Viçosa: Universidade Federal de Viçosa. p.109-119. 